\title{
EXPERTS WARN NEPAL GOVERNMENT NOT TO REDUCE LOCAL PUBLIC HEALTH SPENDING
}

Simkhada $\mathrm{P}^{1}$ Teijlingen $\mathrm{E}^{2}$, Simkhada, $\mathrm{B}^{3}$, Regmi $\mathrm{P}^{4}$, Aryal $\mathrm{N}^{5}$ Marahatta $\mathrm{SB}^{6 *}$

${ }^{1}$ Professor of International Public Health \& Associate Dean (Global Engagement), Faculty of Education, Health and Community, Liverpool John Moores University (LJMU) \& Visiting Professor MMIHS, Nepal

${ }^{2}$ Professor of Reproductive Health Research, Centre for Midwifery, Maternal \& Perinatal Health, Bournemouth University \& Visiting Professor MMIHS, Nepal

${ }^{3}$ Lecturer in Nursing, Bournemouth University, UK

${ }^{4}$ Lecturer in International Health, Bournemouth University, UK; Visiting Research Fellow, Chitwan Medical College, Nepal; Visiting Fellow, Datta Meghe Institute of Medical Sciences, India

Post-Doctoral Researcher, Bournemouth University, UK

${ }^{6 *}$ Professor and Assistant Campus Chief Manmohan Memorial Institute of Health Sciences (MMIHS), Nepal \& Visiting Lecturer Liverpool John Moores University (LJMU) UK

\section{*Corresponding Author}

Dr. Sujan Babu Marahatta, Professor and Assistant Campus Chief, Manmohan Memorial Institute of Health Sciences (MMIHS), Soaltee Mode, Kathmandu, Nepal \& Visiting Lecturer Liverpool John Moores University (LJMU) UK,Email: sujanmarahatta@ gmail.com

The health system in Nepal is currently undergoing some very interesting radical reforms. The new Constitution adopted by Parliament in $2015^{1,2}$ brought a complete restructuring of the country's political system, creating a Federal Republic with seven Provinces. This change involves a significant devolution of power and resources from central to local level in many sectors including the health sector.

Traditionally, the health sector in Nepal has been highly centralized, with the Ministry of Health formulating policies, and providing resources and services for the whole country, i.e. the whole population. At the same time the health system could only function as well as it did with significant external support from NGOs (Non-Governmental Organizations) and INGOs (International NonGovernmental Organizations), and with private provision for those with the means to access it. The new Constitution, by contrast, places responsibility for the provision of health services primarily with the seven new Provinces, with resources being further devolved down to urban and rural municipalities. All of this has put Nepal's health system into a period of rapid and far-reaching change - in both its structure and its way of operating. 
The local governments, elected in 2017, have started to establish themselves in their communities and they are beginning to exert their influence. As these were the first local elections for two decades most of the newly elected local and regional politicians are new to 'being a politician' and to the policy-making process. In other words, they are fairly inexperienced as politicians. One of the ways this shows is in their decision making which seems to prioritize infrastructure development, such as commissioning the building of schools and roads. In health, they are tempted to spend on health facilities and to undertake 'popular' programs. For example, waiving check-up fee for females in government hospital and providing door health services to elderly. We, by no means, believe that this is not a good practice, instead would like to emphasize on carefully planned health programs taking account of locally essential public health needs. Otherwise, Public Health budgets and interventions may be victimized in the race of being popular. If so, this is an understandable mistake as there is a great need in Nepal, especially rural areas for more and better infrastructure and physical developments allow politicians to show their voters that their policies are making a change. The voters can easily see the new road, bridge, school and so on, but it is not so easy to see the increased training of all FCHVs (Female Community Health Volunteers) on contraceptive advice, or Community Health Workers training on counselling. Moreover, the old centralized Ministry of Health had support from a number of experienced Public Health advisors who helped focus the policy-making process as well as the implementation process. Local politicians often lack this detailed in-depth advice from Public Health experts. We expect (and hope) that this deficit of local expertise will disappear over time.

We need to remember that Public Health is not concerned with individual buildings or health services; it aims to improve (a) all people in a population/community; and (b) fight all diseases and illnesses together. This all makes Public Health intervention generic, wide-ranging and perhaps even vague. In other words, less appealing for politicians be associated with and hence to support. If local and regional politicians don't have a wider Public Health perspective and they lack thinking of their citizens' health at a population level, the public health budget ends up being reduced. We acknowledge that the friction between Public Health and curative medicine is not unique to Nepal and that globally Public Health is often the poor relation of medicine, ending up with fewer resources and political support. Public Health interventions or Health Promotion activities are not always attractive because their benefits are often invisible or long-term or poorly understood by the affected population. This lack of immediate benefit to local politicians, or even the local population, means Public Health is likely to receive a lower priority. Over and above the role and status of Public Health in health system funding, there are the specific issues related to and made worse by decentralization. There is a long-running debate in the literature on the costs and benefits of health system decentralization. In theory, decentralization provides a range of benefits, not least in terms of community engagement and responsiveness to the population's health needs, some of which are actually delivered in practice in Nepal. ${ }^{3,4}$

There is one more issue to be considered, namely that global role of Public Health. The work of people in Public Health is wider than municipalities and provinces so strategies and policies need to be national if not international although implementation can be localized. In a globalized world with increasing numbers of travelers, be it for business, tourism and work-related migration, infectious diseases spread much faster than in previous centuries.

In conclusion we like to stress that untrained newly elected representatives with no political experience are most likely to be drawn into proposing and supporting popular measures including developing new 
buildings, black-top roads, hospitals, etc., rather than measures that increase the local or regional budget for teachers, Continuous Professional Development (CPD) for community health workers, and preventative public health measures in general. Buildings and roads are immediate demonstration to voters that politicians have done something useful, reducing maternal mortality by $2.6 \%$ or employing two additional health workers doesn't give politicians neither the same publicity, nor do such policies have immediate signs of success, and hence are unlikely to be vote winners.

This is too early to make any judgment about the on-going changes in Nepal constitutional changes but, we argue, this should be monitored closely. In order to track and monitor such changes Nepal also needs to improve its health and policy research capacity. Academics from high-income countries such as the United Kingdom (UK) can be of help in this research capacity-building process. Let's not forget that Nepal made significant progress on some of the key health-related millennium Development Goals. The latter progress occurred in spite of its relatively poor economic growth due to proper investment on public health. ${ }^{5}$ If Public Health policies, programmes and interventions do not get a greater priority, the country may end up paying a high price in the long-term.

\section{CONFLICT OF INTEREST}

We declare no competing interests.

\section{REFERENCES}

1. Constitution of Nepal 2015. Constituent Assembly Secretariat, Kathmandu; 2015. http://www.wipo.int/edocs/lexdocs/laws/en/np/np029en.pdf. (accessed March 13, 2018)

2. Simkhada P, Regmi, P, Pant, P, van Teijlinge, E , Sathain, B. Stipulating Citizen's Fundamental Right to Healthcare: Inference from the Constitution of Federal Republic of Nepal 2015. Nepal Journal of Epidemiology. 2015; 5: 516-517.

3. Rondinelli, DA, Nellis JR. Assessing Decentralization Policies in Developing Countries: The Case for Cautious Optimism. Development Policy Review. 1986; 4: 3-23.

4. Atkinson S and Haran D. Back to basics: does decentralization improve health system performance? Evidence from Ceará in north-east Brazil. Bulletin of the World Health Organization. 2004; 82: 822-827.

5. Nepal and the Millennium Development Goals: Final Status Report 2000-2015. Nepal Planning Commission, Kathmandu; 2016 https://www.npc.gov.np/images/category/MDG-Status-Report-2016_pdf Iaccessed March 11, 2018). 